\title{
Knowledge and practice of Mothers of under Two Years Children On Complementary Feeding At Bharatpur Hospital, Chitwan, Nepal.
}

\author{
Radha Kumari Paudel ${ }^{1}$ Yuba Nidhi Basaula ${ }^{2}$ Sunita Tiwari ${ }^{3}$ \\ ${ }^{1}$ Radha Kumari Paudel, PhD Scholar, Mewar University, Rajasthan India \\ ${ }^{2}$ Dr Yuba Nidhi Basaula, Senior Consultant Pediatrician, Bharatpur Hospital, Chitwan Nepal \\ ${ }^{3}$ Sunita Tiwari , Associate Professor, Central Department of Home Science, Padma Kanya \\ Multiple Campus, Kathmandu, Nepal
}

\begin{abstract}
Inappropriate complementary feeding practice is one of the main reasons for malnutrition among Nepal children aged less than two years. Exclusive breastfeeding for the first six months followed by complementary feeding along with breastfeeding is vital for proper growth and development of a child. This study was carried out to assess the knowledge and practices of mothers regarding complementary feeding, and to determine the factors influencing the inappropriateness of complementary feeding. A hospital based cross-sectional study was carried out at Bharatpur Hospital Chitwan, Nepal, involving mothers of children from 6 to 24 months of age who attended outpatient department of this hospital, using systematic sampling technique and applying semi-structured questionnaire. About $73.8 \%$ of mothers knew they had to start breast feeding within 1/2-1 hours after birth. It was found in this study that around $20.8 \%$ mothers practiced exclusive breast feeding more than six months. Study shows that $52.30 \%$ mothers had introduced complementary feeds within six months. This study found that 50\% mother fed their children appropriate complementary feeding. About $26.1 \%$ mothers were found to be practicing ideal feeding in this study. It was observed in the study that $73.8 \%$ mothers had knowledge about the exclusive breast feeding. Most mothers (18.4\%) knew when to start complementary feeding. Study shows that 52.30\% mothers had introduced complementary feed within six month. Half of the mothers fed their child appropriate complementary feeding there was a knowledge and practice gap of duration of exclusive breast feeding and initiation and continuation of complementary feeding.
\end{abstract}

\section{KEYWORDS}

Complementary feeding, Exclusive breast feeding,

\section{INTRODUCTION}

Appropriate diet is critical in growth and development of children especially in the first two years of life. Infant and young child feeding practices recommend exclusive breastfeeding up to age of six months, timely initiation of feeding solid, semisolid foods from six months onwards (WHO, 2003). It also recommends feeding small amounts, increasing the amount of foods and frequency of feeding as the child gets older while maintaining breast feeding as demanded by the child. (WHO, 2009). An inadequate complementary food is a major cause of the very high prevalence of malnutrition in the developing world and this may have long-term implications for growth, development, and health (Michaelsen et al., 2003). Complementary feeding is required in appropriate quantity, quality, and frequency to fulfill the daily energy needs for growth and development of child. Cultural practices; 
beliefs and knowledge of parents regarding appropriate feeding practices influence complementary foods. It has been shown in India that only $17.5 \%$ of mothers started complementary feeding at recommended time (at 6 months of age), $77 \%$ had delayed complementary feeding and $5.5 \%$ started complementary feeding early (Gartoulla, 2009).

Malnutrition is a significant health problem for infants and young children in Nepal. Nepal demographic health survey report found that the prevalence of stunting among children of 6- 59 months of age has dropped only by $15.3 \%$ points from $69.5 \%$ in 1975 to $54.2 \%$ in 1998 . This unsatisfactory improvement in nutritional status of children may be partly contributed by inappropriate complementary foods practices (MOHP, 2006). World Health Organization (WHO) has recommended for further research in priority areas to broaden the range of effective interventions and programmatic approaches to improve complementary feeding. Breastfeeding is nearly universal in Nepal, and half of the children born in the three years before the survey were breastfed for about 34 months or longer. Seventy percent of children less than age 6 months were exclusively breastfed and the median duration of exclusive breastfeeding was 4.2 months. Seventy percent of breastfed children had been given complementary food by age 6-9 months. Overall only one-fourth of children age 6-23 months were fed appropriately based on recommended infant and young child feeding practices.

The most recent estimates of the global burden of malnutrition in under 5 children are that 178 million (one-third of all children) are stunted, 112 million are underweight, 55 million are wasted (19 million having severe acute malnutrition) and 13 million children are born each year with intrauterine growth retardation (Ramji, 2009, p. 624). In this world, 800 million people are suffering from undernourishment and about 170 million infants and young children are underweight. More than 5 million children die each year as a result of under-nutrition (Nutrition, 2006 , p. 1) . The level of childhood malnutrition is exceptionally high in South Asia, ranging from 45-48\% in India, Bangladesh and Nepal , 38\% in Pakistan and 30\% in Sri Lanka (Wijesinghe, 2010, p. 1).Severe acute malnutrition (SAM) is estimated to affect about 20 million children under five years of age globally (UNICEF, 2012). Understanding the effect of infant and young child feeding (IYCF) practices on improving the nutritional status of children under two years of age, the World Health Organization developed a set of core indicators to assess infant and young child feeding (IYCF) practices (IFPRI, 2008 ,2010). These indicators incorporated both breast-feeding and complementary feeding linked practices. Appropriate feeding practices, therefore, include timely initiation of feeding of solid and semi-solid foods from age 6 months and to improve the quantity and quality of foods children consume, while maintaining breastfeeding (UNICEF, WHO, 2010).

There are limited studies on knowledge and practices about complementary feeding. The findings of this study will be useful for the health planning and policy to improve feeding practices in country. The Knowledge on feeding practices of infants and young children is essential for improving health and nutrition program in a country. Promotion of optimal breast feeding and complementary feeding has been expected as a key priority of Ministry of Health and population. The aim of the study was to identify the knowledge of mothers concerning complementary feeding and to assess the factors influencing the practice of complementary feeding for improve the child feeding practice and reduce child mortality and morbidity. 


\section{MATERIALS AND METHODS}

A descriptive cross sectional study was conducted among children under the age of two years. Ethical approval was taken from institute review board of PadmaKanya Multiple College, Kathmandu and formal consent with the respective hospital directors and verbal consent the respondents was taken before data collection. Altogether 130 children and their parents were selected for this study by using the Probability, systematic sampling method. A mother attending in pediatric outpatient department (OPD) was sampling frame. Every even ticket number of children's mother from the outpatient department was interviewed per day for required sample size. Collected data and information were analyzed and interpreted with quantitative descriptive method.

Complementary feeding practices were assessed using the key indicators recommended by the WHO and UNICEF which include introduction of solid, semi-solid or soft foods, minimum dietary diversity, minimum meal frequency and minimum acceptable diet calculated for the age ranges 6-11, 12-17 and 18-23 months of age, and based on a 24-hour recall of the child's dietary intake. These indicators include timely introduction of solid, semi-solid or soft foods, seven food groups. Minimum meal frequency and minimum acceptable diet (IFPRI, 2008, 2010).

\section{RESULTS}

\section{Demographics characteristics of respondent}

Majority $(80.8 \%)$ of the mother were $20-30$ years old, $10.8 \%$ were below 20 years. About $10.8 \%$ mothers were illiterate, $20 \%$ had studied bachelor degree. Nuclear family system was more common than joint family (70\% vs. 30\%). Likewise, majority of the respondents were from rural area $(41.5 \%)$, followed by town $(40 \%)$ and rest were from city areas (Table 1).

Table 1: Socio demographic of respondents $(n=130)$

\begin{tabular}{|c|c|c|}
\hline & Variables & Percentage (\%) \\
\hline \multirow[t]{4}{*}{1} & Age of respondent(Mother) & \\
\hline & S.N & 10.8 \\
\hline & $20-30 \mathrm{yrs}$. & 80.8 \\
\hline & $31-40$ yrs. & 8.5 \\
\hline \multirow[t]{6}{*}{2} & Education & \\
\hline & Uneducated(illiterate) & 10.8 \\
\hline & Educated(literate) & 50.8 \\
\hline & Primary & 7.7 \\
\hline & Secondary & 20 \\
\hline & Higher secondary & 10.8 \\
\hline \multirow[t]{3}{*}{3} & Family Structure & \\
\hline & Joint & 30 \\
\hline & Nuclear & 70 \\
\hline \multirow[t]{4}{*}{4} & Residence & \\
\hline & City & 18 \\
\hline & Town & 40 \\
\hline & Rural & 42 \\
\hline
\end{tabular}


Table 2 shows the majorities (56.15\%) of the children were male and only $43.8 \%$ of the children were female. More than half (51.5) of the children were of age group 6-12 months and only $20.04 \%$ were of age group 18-24 months.

Table 2: Distribution by sex and age group of children

\begin{tabular}{llc}
\hline S.N & Variables & Percentage (\%) \\
$\mathbf{1}$ & Sex of child & \\
& Male & 56.15 \\
& Female & 43.8 \\
$\mathbf{2}$ & Age of child( in month) & \\
& 6-12 & 51.5 \\
& $13-17$ & 28.46 \\
& $18-23$ & 20.04 \\
\hline
\end{tabular}

Table 3 shows that majority (57.1\%) of literate mother said they start complementary foods, within 6 months, about $46.9 \%$ of literate mother said they fed 4 times a day, only $24.2 \%$ mothers fed appropriately but $63.6 \%$ mothers fed appropriate consistency. National demography health survey 2011, result showed, children whose mothers were well educated and had a secondary level education or higher education were more likely to meet the minimum dietary diversity compared to children whose mothers did not have any formal education (Zhao, 2013). It was found that mothers' education was strongly associated with the appropriate feeding. Educated mother had high rate of feeding practices (initiation, timing, amount and consistency) than the uneducated mother.

Table 3: Mother's education related characteristics for proper initiation, timing, amount and consistency of feeding influencing factors $(n=130)$

\begin{tabular}{|c|c|c|c|c|c|c|c|c|c|c|c|c|}
\hline \multirow{7}{*}{ 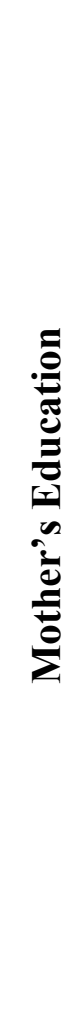 } & \multirow{3}{*}{$\begin{array}{l}\text { Education } \\
\text { Level } \\
\text { Illiterate }=14(10.8 \% \\
\quad)\end{array}$} & \multicolumn{3}{|c|}{ Initiation of $\mathbf{C F}$} & \multicolumn{3}{|c|}{ Feeding time a day } & \multicolumn{2}{|c|}{$\begin{array}{c}\text { Amount of } \\
\text { CF }\end{array}$} & \multicolumn{3}{|c|}{ Consistency of CF } \\
\hline & & 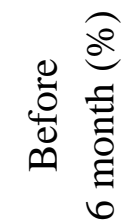 & 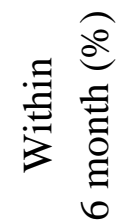 & 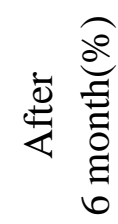 & 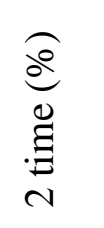 & $\begin{array}{l}\underset{8}{0} \\
\stackrel{g}{\Xi} \\
m\end{array}$ & $\begin{array}{l}\underset{8}{8} \\
\stackrel{8}{\Xi} \\
\dot{8}\end{array}$ & 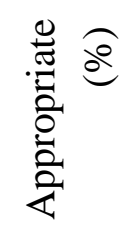 & 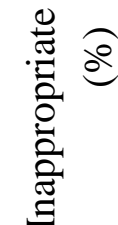 & $\frac{\widehat{d}}{\frac{a}{0}}$ & $\begin{array}{l}\underset{\Xi}{E} \\
\stackrel{\Xi}{E}\end{array}$ & 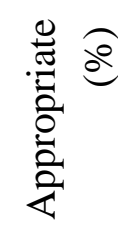 \\
\hline & & 100 & - & - & 28.5 & 21.4 & 50 & - & 100 & 57.1 & 14.2 & 28.5 \\
\hline & $\begin{array}{l}\text { literate } \\
\mathrm{n}=66(50.8 \%)\end{array}$ & 27.2 & 57.5 & 15.1 & 9.09 & 43.9 & 46.9 & 24.2 & 75.7 & 18.1 & 18.1 & 63.6 \\
\hline & $\begin{array}{l}\text { Primary } \\
n=10(7.7 \%)\end{array}$ & 20 & 70 & 10 & 10 & 60 & 30 & 20 & 80 & 20 & 50 & 30 \\
\hline & $\begin{array}{l}\text { Secondary } \\
n=26(20 \%)\end{array}$ & - & 61.5 & 38.4 & 7.6 & 57.6 & 34.6 & 46.1 & 53.8 & 15.3 & 38.4 & 46.1 \\
\hline & $\begin{array}{l}\text { Higher Secondary } \\
n=14(10.8 \%)\end{array}$ & 7.14 & 50 & 42.8 & - & 57.1 & 42.8 & 28.5 & 71.4 & 21.4 & 57.1 & 21.4 \\
\hline
\end{tabular}




\section{DISCUSSION}

This study was carried out to assess the knowledge of mothers concerning complementary feeding, to assess the practices of complementary feeding in terms of quantity, quality and timing and to identify the factors influencing the inappropriateness of complementary feeding.

About $73.8 \%$ of mothers knew they had to start breast feeding within $1 / 2-1$ hours after birth and $26.2 \%$ mothers did not have the knowledge about it. Our result is comparable with global situation. Worldwide, it is estimated that only $34.8 \%$ of infants are exclusively breastfed for the first 6 months of life and majority of them receive some other foods or fluids in the early months of life. Similarly, exclusive breast-feeding for 6 months was given only to 10.5\% of infants (Dashti et al., 2010). Majority (76.9\%) of mothers were aware about the proper time (after six months) to introduce complementary feeding for their children. Mothers who reported giving complementary food after six months were (20.8\%). Majority of the mother (93.1\%) had knowledge about first start of soft semisolid food and only $2.3 \%$ of mothers had no idea for first introducing complementary food. Similarly study shows that $52.30 \%$ mothers had introduced complementary feeds within six month. Majority $(83 \%)$ of the mothers told that for health of their child they started complementary foods, The National demographic health survey 2011 concluded that complementary foods are not introduced in a timely for all children in Nepal. Seventy percent of infants have been given complementary foods by age 6-9 months. Study showed that $7.7 \%$ of the mothers offered only lito for complementary food, around $21.5 \%$ mothers used jaulo and $70.8 \%$ of the mother offered rice pudding as the first complementary feeding. According to our cultural beliefs in Nepal; a child has to be fed rice/rice pudding when he/she turns six months old.

Majority (95.3\%) of the mothers fed grains, cereals, pulses and rice product during complementary foods. About, half of the mothers fed their child appropriate consistency. Consistency of complementary feeding is one of the important components of appropriate complementary feeding. The study done in India found the $25.5 \%$ to $30.0 \%$ mothers knew and practiced the recommended complementary feeding by consistency which is lower than my finding. Consistency of complementary feeding is one of the important components of appropriate complementary feeding. This might be one of the possible factors for high prevalence of under-nutrition, wasting and stunting despite the use of correct amount of feeding.

In computing the ideal feeding only $26.1 \%$ of mothers fed their child normal amount and $73.8 \%$ fed their child inappropriate amount. This finding is very contrasting with the finding of national demography health survey, 2011 which reported that about three out of five children $(57.0 \%)$ were fed according to recommendation given by Infant and young child feeding in terms of foods from recommended food groups and were fed at least the recommended minimum number of time.

\section{CONCLUSIONS}

This study found results on knowledge and practice of mothers concerning infant and young child feeding. The prevalence of timely initiation of complementary feeding at 6 months, minimum dietary diversity, minimum feeding frequency and minimum acceptable diet were low. There were a big knowledge and practice gap of duration of exclusive breast feeding and initiation and continuation of ideal complementary feeding, and increase the appropriate feeding practices by putting more effort in consistency of food and timing of feeding. 


\section{REFERENCES}

Dashti M., Scott, J.A., Edwards, C.A., AI-Sughayer, M. (2010). Determinants of Breastfeeding Initiation among Mothers in Kuwait. International Breastfeeding , 5 (7).

Gartoulla, R. K. (2009). Nepal Nutrition Assessment and Gap analysis final report.

Michaelsen, K.M., Weaver, L., Branca, F., Robertson, A. (2003). Feeding and nutrition of infant and children, guideline for the WHO europeean region with emphasis on the former soviet countries.

WHO regional, Europeian series 87.

MOHP. (2006). Nepal Demographic Health Survey. New ERA Macro International Inc.Calverton, Maryland, U.S.A.

MOHP, New ERA and ICF International. (2011). Nepal demographic health survey key findings. kathmandu nepal: New ERA,Macro International Inc. Calverton, Maryland, U.S.A.

Nutrition, U. n. (2006 ). Double Burden of Malnutrition - A Common Agenda. Standing Committee on Nutrition . Geneva, Switzerland,

Population Division, M. G. (2011). Nepal Demographic and Health Survey. E-mail:

reports@measuredhs.com, Internet: http://www.measuredhs.com., Kathmandu Nepal.

Ramji, S. ( 2009, November). Impact of infant \& young child feeding \& caring practices on nutrition status and health. Indian J Med Res , 624-626.

UNICEF. (2012). Evaluation of Community Management of Acute Malnutrition (CMAM): Nepal Country Case Study. New York.

WHO. (2009). Infant and Young Child Feeding: Model Chapter for Textbooks for Medical Students and Allied Health Professionals. Geneva.

WHO, UNICEF. (2006). child growth standards and the identification of severe acute malnutrition in infant and children.

WHO.UNICEF.USAID, FNATA, AED, UC DAVIS, and IFPRI. (2008). Indicators for assessing infant and young child feeding practices part-1. Gebeva: WHO.

WHO.UNICEF.USAID,FNATA, AED, UC DAVIS, and IFPRI. (2008,2010). Indicators for assessing infant and young child feeding practices PART-1 \& 3. Geneva: WHO.

Wijesinghe, T. P. (2010). Nutritional Status of under 5 Year-Old Children and its Relationship with Maternal Nutrition Knowledge in Weeraketiya DS division of Sri Lanka . Tropical Agricultural Research, 21 (4), 330 - 339.

Zhao, V. K. (2013). Determinants of complementary feeding practices among Nepalese children aged 6-23months: findings from demographic and health survey 2011. BMC Pediatrics , 13 (131), 13. 